\title{
Sex hormone modulation of proinflammatory cytokine and C-reactive protein expression in macrophages from older men and postmenopausal women
}

\author{
Michael P Corcoran ${ }^{1}$, Mohsen Meydani ${ }^{2}$, Alice H Lichtenstein ${ }^{3}$, Ernst J Schaefer ${ }^{1}$, Alice Dillard ${ }^{3}$ \\ and Stefania Lamon-Fava ${ }^{1}$ \\ ${ }^{1}$ Lipid Metabolism Laboratory, ${ }^{2}$ Vascular Biology Laboratory and ${ }^{3}$ Cardiovascular Nutrition Laboratory, Jean Mayer USDA Human Nutrition Research Center on \\ Aging, Tufts University, 711 Washington Street, Boston, Massachusetts 02111, USA \\ (Correspondence should be addressed to S Lamon-Fava; Email: stefania.lamon-fava@tufts.edu)
}

\begin{abstract}
Inflammation plays a central role in the development and progression of coronary heart disease (CHD). The sex hormones estrogen and testosterone have been shown to modify the inflammatory response by influencing cytokine expression in human macrophages obtained from younger individuals. The effect of these hormones on the expression of proinflammatory markers in macrophages obtained from a CHD age-relevant population has not been studied. Human monocyte-derived macrophages (HMDMs) were obtained from healthy normolipidemic men and postmenopausal women (age 50-70 years), and cultured in autologous serum along with both physiological and supraphysiological concentrations of estrogen or testosterone. HMDMs were stimulated with oxidized low-density lipoproteins, and the expression of the cytokines tumor necrosis factor $\alpha$ (TNF- $\alpha$ or TNF), interleukin (IL)6, and IL-1 $\beta$ (IL1B) and of the
\end{abstract}

acute-phase protein C-reactive protein (CRP) was measured. Both physiological and supraphysiological concentrations of testosterone reduced the expression and secretion of TNF- $\alpha$ and reduced the expression of IL- $1 \beta$, but did not affect the expression of IL6 or CRP. Estrogen did not modify the expression of TNF- $\alpha$, IL6, and IL-1 $\beta$. Estrogen caused a variable response in CRP expression that was positively associated with the plasma small dense LDL-cholesterol concentration of the donors. There were no gender differences in any of the observed effects. Our results indicate that testosterone may exert anti-inflammatory effects by reducing macrophage TNF- $\alpha$ expression, while the effects of estrogen on macrophage CRP expression may depend upon the extracellular lipid environment.

Journal of Endocrinology (2010) 206, 217-224

\section{Introduction}

The pathology of coronary heart disease (CHD) is complex and multifaceted, with inflammation playing a central part (Libby 2002). Peripheral blood monocytes recruited into the intima-media layer of an artery play a pivotal role in the local inflammation (Brown \& Goldstein 1983). Recruited monocytes differentiate into macrophages and begin to take up oxidized lipoproteins, leading to the formation of foam cells. Foam cells are a primary component of early atheroma lesion formation (Lloyd-Jones et al. 2009), and are a significant source of proinflammatory cytokines (Tipping \& Hancock 1993), which include tumor necrosis factor $\alpha$ (TNF- $\alpha$ or TNF), interleukin (IL) 6 , and IL-1 $\beta$ (IL1B). These cytokines actively participate in atherogenesis by promoting endothelial dysfunction, further monocyte recruitment, and smooth muscle cell apoptosis (Valente et al. 1992).

C-reactive protein (CRP) is an acute-phase protein that serves as a marker of systemic inflammation, and has been shown to be an independent predictor of CHD risk (Torres \&

Ridker 2003). Most circulating CRP is secreted by the liver, yet a small amount of CRP is produced by macrophages present in atherosclerotic plaques (Yasojima et al. 2001). Levels of CRP mRNA and protein have been found to be up to tenfold higher in arterial plaque tissue than in the normal artery, suggesting that at least a portion of atheroma CRP content is locally produced (Kobayashi et al. 2003). In vitro and animal studies indicate that CRP may actively participate in plaque development by promoting endothelial dysfunction (Bisoendial et al. 2007), monocyte adhesion to the endothelium ( $\mathrm{Li}$ et al. 2004), macrophage cholesterol accumulation (Singh et al. 2008), and fibrin breakdown (reduced plaque stability; Williams et al. 2004).

The steroid hormones $17 \beta$-estradiol $\left(\mathrm{E}_{2}\right)$ and testosterone are thought to play a role in modulating inflammation and thereby influencing atherogenesis. In postmenopausal women, $\mathrm{E}_{2}$ replacement therapy does not affect circulating TNF- $\alpha$ and IL6 concentrations (Pradhan et al. 2002, Zegura et al. 2003). However, hormone treatment may cause changes in cytokine levels in the arterial lesions that may not be 
entirely predicted by plasma cytokine levels. Very little work has been conducted examining the effect of $E_{2}$ on cytokine expression in human monocyte-derived macrophages (HMDMs), with one study showing that $\mathrm{E}_{2}$ withdrawal results in greater proinflammatory cytokine expression in female premenopausal HMDMs after $24 \mathrm{~h}$ of treatment than in HMDMs continually exposed to the hormone for $48 \mathrm{~h}$ (Kramer et al. 2004). Using testosterone, the expression of TNF- $\alpha$, IL6, and IL-1 $\beta$ was shown to be reduced both in rodent macrophage cell models and in human monocytes obtained from younger individuals (Chao et al. 1995, Kanda et al. 1996, 1997, D’Agostino et al. 1999); yet, no studies have been done in HMDMs obtained from older individuals. The effect of $E_{2}$ and testosterone on CRP expression in HMDMs has not been studied. The purpose of this study was to assess the effect of $E_{2}$ and testosterone treatment on the expression of proinflammatory cytokines and CRP by macrophages obtained from a CHD age-relevant population.

\section{Materials and Methods}

\section{Materials}

$\mathrm{E}_{2}$ and testosterone were purchased from Sigma-Aldrich. Phenol-free RPMI1640 medium was purchased from Gibco. Ficoll-Paque was obtained from GE Healthcare (Piscataway, NJ, USA). RNeasy mini kit was purchased from Qiagen. Penicillin, streptomycin, and SuperScript III Reverse Transcriptase kit were obtained from Invitrogen. Power SYBR Green Master Mix was purchased from Applied Biosystems (Carlsbad, CA, USA). Bicinchoninic Acid Protein Assay kit was obtained from Pierce (Rockford, IL, USA).

\section{Subjects}

Male $(n=10)$ and postmenopausal female $(n=10)$ volunteers between 50 and 70 years of age were recruited. Subjects were included if they reported no history of CHD; cancer; diabetes; or renal, liver, or thyroid disease. Subjects who smoked or had hypertension were excluded from the study. Volunteers were not taking any medications to control plasma lipid or glucose levels. Inclusion criteria were low-density lipoprotein cholesterol (LDL-C) $<160 \mathrm{mg} / \mathrm{dl}$, high-density lipoprotein cholesterol (HDL-C) $\geq 40 \mathrm{mg} / \mathrm{dl}$, triglycerides (TG) $<150 \mathrm{mg} / \mathrm{dl}$, and glucose $\leq 100 \mathrm{mg} / \mathrm{dl}$. Women were considered postmenopausal if absence of menstrual periods exceeded 1 year. Most women $(n=8)$ in this study had been postmenopausal for $>5$ years. Lastly, because it had been reported that the estrogen receptor $\alpha(E R \alpha$ or ESR1) gene polymorphism IVS1-401 T/C, located within the first intron, can affect the plasma lipid response to $\mathrm{E}_{2}$ (Herrington et al. 2002), volunteers were genotyped for this mutation, and subjects with the IVSI C/C genotype were excluded. Characteristics of the subjects are given in Table 1.
Table 1 Characteristics and fasting metabolic and lipid profile of the study volunteers. Values are expressed as means (s.D.)

\begin{tabular}{|c|c|c|c|}
\hline & $\begin{array}{l}\text { Women } \\
(n=10)\end{array}$ & $\begin{array}{l}\text { Men } \\
(n=10)\end{array}$ & $P$ value* \\
\hline Age (years) & $59(4)$ & $61(6)$ & $0 \cdot 423$ \\
\hline $\mathrm{BMI}\left(\mathrm{kg} / \mathrm{m}^{2}\right)$ & $27 \cdot 6(6 \cdot 2)$ & $26 \cdot 0(2 \cdot 9)$ & $0 \cdot 481$ \\
\hline \multicolumn{4}{|l|}{ Lipids } \\
\hline $\mathrm{TC}(\mathrm{mg} / \mathrm{dl})$ & $206(31)$ & $178(34)$ & $0 \cdot 069$ \\
\hline LDL-C (mg/dl) & $111(33)$ & $87(36)$ & $0 \cdot 136$ \\
\hline sdLDL-C (mg/dl) & $26(8)$ & $29(13)$ & $0 \cdot 555$ \\
\hline HDL-C (mg/dl) & $66(16)$ & $46(16)$ & $0 \cdot 011^{*}$ \\
\hline $\mathrm{TG}(\mathrm{mg} / \mathrm{dl})$ & $78(28)$ & $99(46)$ & $0 \cdot 229$ \\
\hline Glucose (mg/dl) & $91(7)$ & $91(8)$ & 0.976 \\
\hline Plasma CRP $(\mu \mathrm{g} / \mathrm{ml})$ & $3 \cdot 9(3 \cdot 6)$ & $1 \cdot 4(0.91)$ & $0 \cdot 053$ \\
\hline $\mathrm{ER} \alpha \mathrm{IVS} 1$ & $\begin{array}{c}\mathrm{T} / \mathrm{C}=5, \\
\mathrm{~T} / \mathrm{T}=5\end{array}$ & $\begin{array}{c}\mathrm{T} / \mathrm{C}=8, \\
\mathrm{~T} / \mathrm{T}=2\end{array}$ & $0 \cdot 349$ \\
\hline
\end{tabular}

${ }^{*} P$ value for gender difference.

Plasma lipid measurements and LDL isolation and oxidation

Plasma lipid levels were determined using enzymatic assays (Roche Diagnostics). Plasma levels of small dense LDL-C (sdLDL-C) were assessed using an enzymatic assay (Denka Seiken Corporation, Tokyo, Japan) as described previously (Ai et al. 2008). Plasma CRP levels were measured using a highsensitivity immunoturbidimetric assay (Roche Diagnostics).

LDLs were isolated from the pooled plasma of the donors by rapid single-step ultracentrifugation using a Beckman NVT90 rotor as described previously (Vieira et al. 1996). After desalting, LDLs were oxidized by the addition of $100 \mu \mathrm{M} \mathrm{CuSO}_{4} / 100 \mu \mathrm{g}$ protein. Oxidation extent was monitored by the formation of conjugated dienes at $234 \mathrm{~nm}$. When absorbance began to increase exponentially $(\approx 1.5 \mathrm{~h})$, LDLs were placed on ice and immediately desalted using chromatography columns (Bio-Rad Laboratories) to stop further oxidation. This typically produced a thiobarbituric acid-reactive substance (TBARS) value of 6-8 nM malondialdehyde $/ \mu \mathrm{g}$ protein. TBARS measurements were performed as described previously (Cathcart et al. 1991). The moderately oxidized LDLs (oxLDL) were stored at $-80^{\circ} \mathrm{C}$ in the dark for up to 2 months, as TBARS values and $234 \mathrm{~nm}$ readings were found to remain stable for this duration. The same batch of oxLDLs was used for all the experiments.

\section{Isolation and culture of HMDMs}

Blood was drawn in tubes containing 0.1\% EDTA and centrifuged at $250 \mathrm{~g}$ for $30 \mathrm{~min}\left(25^{\circ} \mathrm{C}\right)$ to remove plasma. Buffy coats were obtained by layering blood diluted 1:2 with RPMI culture medium over Ficoll-Paque followed by centrifugation $\left(37 \mathrm{~min}, 500 \mathrm{~g}, 25^{\circ} \mathrm{C}\right.$ ). White blood cells were collected and washed twice with RPMI medium. Cells were plated in RPMI medium containing $100 \mathrm{U} / \mathrm{ml}$ penicillin and $100 \mu \mathrm{g} / \mathrm{ml}$ streptomycin. After $3-5 \mathrm{~h}$ of incubation at $37^{\circ} \mathrm{C}$ in $5 \% \mathrm{CO}_{2}$, nonadherent cells were washed off, and the remaining monocytes were cultured in 
RPMI medium containing 10\% autologous serum. Cells were allowed to differentiate for 10 days in the presence of vehicle (ethanol), $\mathrm{E}_{2}(2$ or $20 \mathrm{nM})$, or testosterone (10 or $\left.100 \mathrm{nM}\right)$, with the medium being changed every 3-4 days. $\mathrm{E}_{2}$ and testosterone solutions were prepared fresh under sterile conditions every 2 weeks by dissolving in 100\% ethanol, and were stored in the dark at $-80{ }^{\circ} \mathrm{C}$. HMDMs were treated with $50 \mu \mathrm{g} / \mathrm{ml}$ oxLDL for $48 \mathrm{~h}$ (days 11-12) in the presence of $10 \%$ autologous serum and hormone, and were then exposed to hormones in addition to the medium without serum for an additional $24 \mathrm{~h}$. The serum-free medium was collected, centrifuged to remove cell debris, and stored at $-80{ }^{\circ} \mathrm{C}$. Cells were collected in a lysis buffer $(0 \cdot 1 \mathrm{M}$ $\mathrm{KH}_{2} \mathrm{PO}_{4}, 0 \cdot 05 \mathrm{M} \mathrm{NaCl}, 5 \mathrm{mM}$ cholic acid, and $0 \cdot 1 \%$ Triton $\mathrm{X}-100)$, and the cell protein was quantified using the bicinchoninic acid method with BSA as a standard.

\section{Real-time PCR}

Total cellular RNA was isolated using the RNeasy mini kit according to the manufacturer's instructions. Hundred nanograms of RNA were reverse transcribed using the SuperScript III Reverse Transcription kit, and were amplified on a real-time PCR system 7300 using specific primers. The primer sequences were as follows: $\beta$-actin ( $F^{\prime}$-TGAAGTGTGACGTGGACATCC and $\mathrm{R}^{\prime}$-CTCAGGAGGAGCAATGATCTTG), TNF- $\alpha$ (F'-TGGAGAAGGGTGACCGACTC and $\mathrm{R}^{\prime}$-TCCTCACAGGGCAATGATCC),
IL6 (F'-GTGGCTGCAGGACATGACAA and R'-TGAGGTGCCCATGCTACATTT), IL-1 $\beta$ (F'-TTATTACAGTGGCAATGAGGATGAC and R'-CGCCATCCAGAGGGCAG), CRP (F'-ATTCAGGCCCTTGT-ATCACTGG and $\mathrm{R}^{\prime}$-AACAGCTTCTCCATGGTCACG), androgen receptor (AR) (F'-GACTCCGTGCAGCCTATTGC and R'-TCTGCCATCATTTCCGGAA), ER $\alpha$ or ESR 1 (F'-CGGCATTCTACAGGCCAAA and $\mathrm{R}^{\prime}$-GCGAGTCTCCTTGGCAGATTC), and ER $\beta$ or ESR2 (F'-TACAATCGATAAAAACCGGCG and $\mathrm{R}^{\prime}$-GGGAGCCACACTTCACCATT). Primers were designed using Primer Express software (Foster City, CA, USA), included intron/exon boundaries, and were validated for efficiency and specificity using the standard curve dilution and melting point analyses. Real-time PCR was carried out for 40 cycles at $95^{\circ} \mathrm{C}(15 \mathrm{~s})+60{ }^{\circ} \mathrm{C}(1 \mathrm{~min})$ using the Power SYBR Green Master Mix. Changes in gene expression were assessed by $\Delta \Delta C_{\mathrm{t}}$ analysis with $\beta$-actin as the control/housekeeping gene. Changes were expressed as the percent of control (vehicle only).

\section{TNF- $\alpha$ ELISA}

TNF- $\alpha$ concentration in the cell culture medium was measured using an ultrasensitive human TNF- $\alpha$ ELISA kit according to the manufacturer's instructions (Alpco Diagnostics, Salem, NH, USA). The final TNF- $\alpha$ concentrations were adjusted for cell protein.
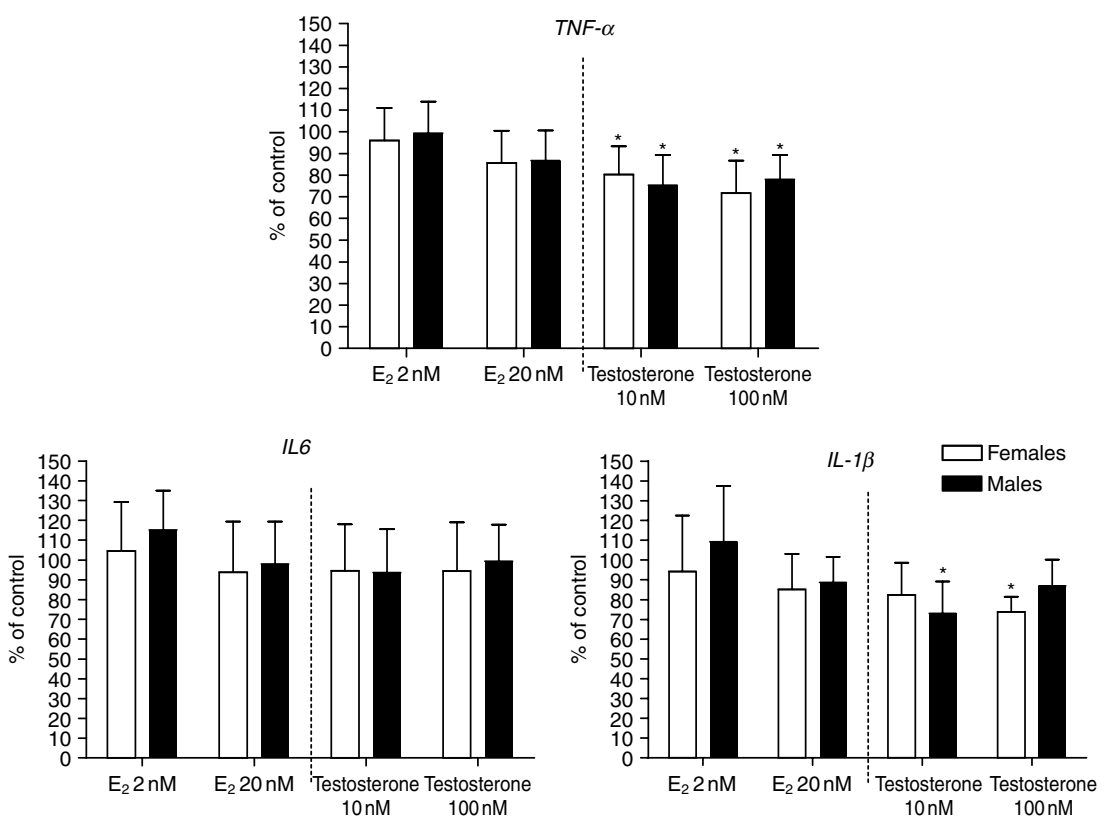

Figure 1 Effect of $E_{2}$ or testosterone treatment on proinflammatory cytokine expression in HMDMs. HMDMs were cultured in 10\% autologous serum and differentiated over 10 days in the presence of vehicle (control), $2 \mathrm{nM} \mathrm{E}_{2}, 20 \mathrm{nM} \mathrm{E}_{2}, 10 \mathrm{nM}$ testosterone, or $100 \mathrm{nM}$ testosterone. HMDMs were then exposed for $48 \mathrm{~h}$ to oxLDLs with the hormone. RNA was isolated, and the expression of proinflammatory cytokines was measured. Data are expressed as the percent of control; ${ }^{*} P<0 \cdot 05$. 


\section{Statistical analyses}

Statistical analyses were performed using SAS software (version 9.1; SAS Institute, Cary, NC, USA), while correlations were determined using GraphPad Prism software (version 4; La Jolla, CA, USA). Gene expression results are expressed as the percent of control (vehicle treatment only). Means and s.D. are representative of the treatment response in macrophage cultures donated by ten females or ten males. Statistical differences were determined by two-way ANOVA for both treatment effect and sex effect using Tukey's Student Range test.

\section{Results}

Both hormone receptors $A R$ and $E R \alpha$ were expressed in HMDMs (average $C_{\mathrm{t}}$ of 33 and 32 respectively, on real-time PCR, compared with an average $C_{\mathrm{t}}$ of 24 for $\beta$-actin). There was no difference in the expression of $A R$ between female and male HMDMs, while the expression of $E R \alpha$ was threefold higher in female HMDMs than in male HMDMs. The expression of $E R \beta$ was too low to be accurately quantified $\left(C_{\mathrm{t}}>36\right)$.

$\mathrm{E}_{2}$ treatment did not significantly affect the expression of $T N F-\alpha, I L 6$, and $I L-1 \beta$ in HMDMs (Fig. 1). Relative to control, both physiological and pharmacological concentrations of testosterone significantly reduced $T N F-\alpha$ expression in HMDMs obtained from both males and females (Fig. 1). These reductions averaged $20-25 \%$ at $10 \mathrm{nM}$ and $25-30 \%$ at $100 \mathrm{nM}$ (Fig. 1). TNF- $\alpha$ concentration in the medium was measured in the vehicle-, $2 \mathrm{nM} \mathrm{E}_{2^{-}}$, and $10 \mathrm{nM}$ testosterone-treated cells (Fig. 2). Similar to the effect on gene expression, testosterone treatment, but not $\mathrm{E}_{2}$ treatment,

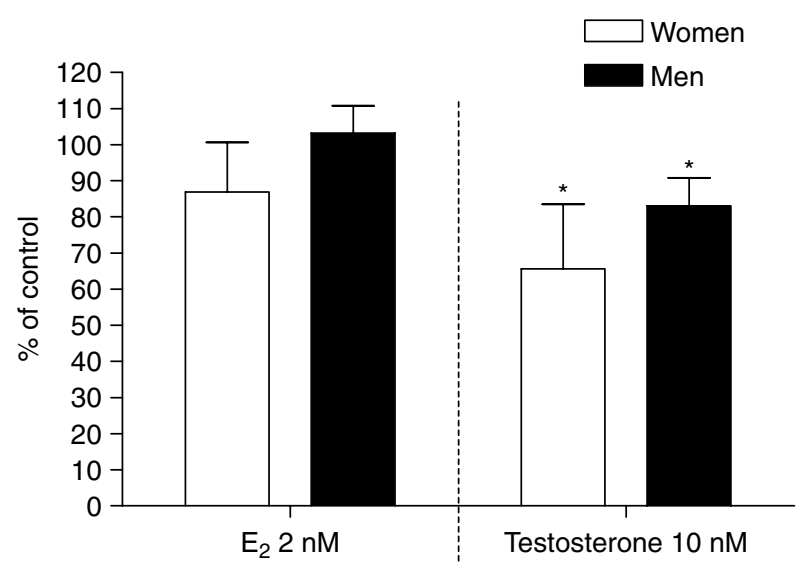

Figure 2 Effect of $E_{2}$ or testosterone treatment on TNF- $\alpha$ secretion by HMDMs. As described in Fig. 1, HMDMs were differentiated for 10 days in $10 \%$ autologous serum and the corresponding hormone, and were then exposed to oxLDLs for $48 \mathrm{~h}$, followed by exposure to the medium without serum for $24 \mathrm{~h}$. Indicated hormone was given for the entire duration of the experiment. Medium was collected, and TNF- $\alpha$ concentration was measured and adjusted for cell protein. Data are expressed as the percent of control; ${ }^{*} P<0 \cdot 05$.

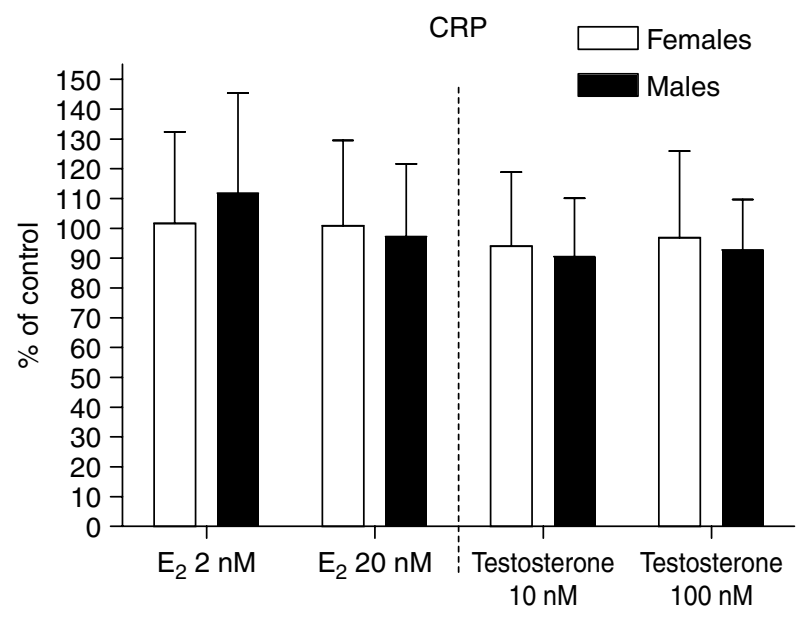

Figure 3 Effect of $E_{2}$ or testosterone treatment on HMDM CRP expression. HMDMs were cultured as described in Fig. 1, and the expression of CRP was measured. Data are expressed as the percent of control.

significantly reduced HMDM TNF- $\alpha$ secretion, compared with the control. There was no statistical difference between the genders. Testosterone treatment significantly reduced $I L-1 \beta$ expression at $10 \mathrm{nM}$ in males and at $100 \mathrm{nM}$ in females, but it did not affect IL6 expression (Fig. 1).

The effect of $\mathrm{E}_{2}$ on $C R P$ expression was variable in both women and men (Fig. 3). The change in CRP expression by HMDMs in response to $E_{2}$ treatment, but not in response to testosterone treatment, was positively associated with the concentration of sdLDL-C in the plasma of the donors (Fig. 4A and B). Donors with plasma sdLDL-C $>30 \mathrm{mg} / \mathrm{dl}$ showed a significant increase in HMDM CRP expression with estrogen treatment, whereas there was no effect in HMDMs obtained from donors with sdLDL-C $<30 \mathrm{mg} / \mathrm{dl}$ (Fig. 4C). This effect was gender independent. The change in CRP expression with $\mathrm{E}_{2}$ was not associated with other parameters (age, body mass index, other plasma lipid, or CRP levels).

\section{Discussion}

The effect of sex hormones on macrophage inflammation is an important area of investigation because of the contribution of inflammation to CHD. The hormone receptors AR and ER, which are expressed in both male and female HMDMs, are the likely mediators of the effects of sex hormones on macrophage function (Cutolo et al. 1996). Low serum testosterone levels in men have been associated with increased atheroma formation (Hak et al. 2002). In addition, hypogonadal men have been found to have higher serum cytokine levels than healthy men, and androgen supplementation was found to reduce these levels (Yesilova et al. 2000). Testosterone treatment has been shown to suppress cytokine expression in rodent macrophages and in human 

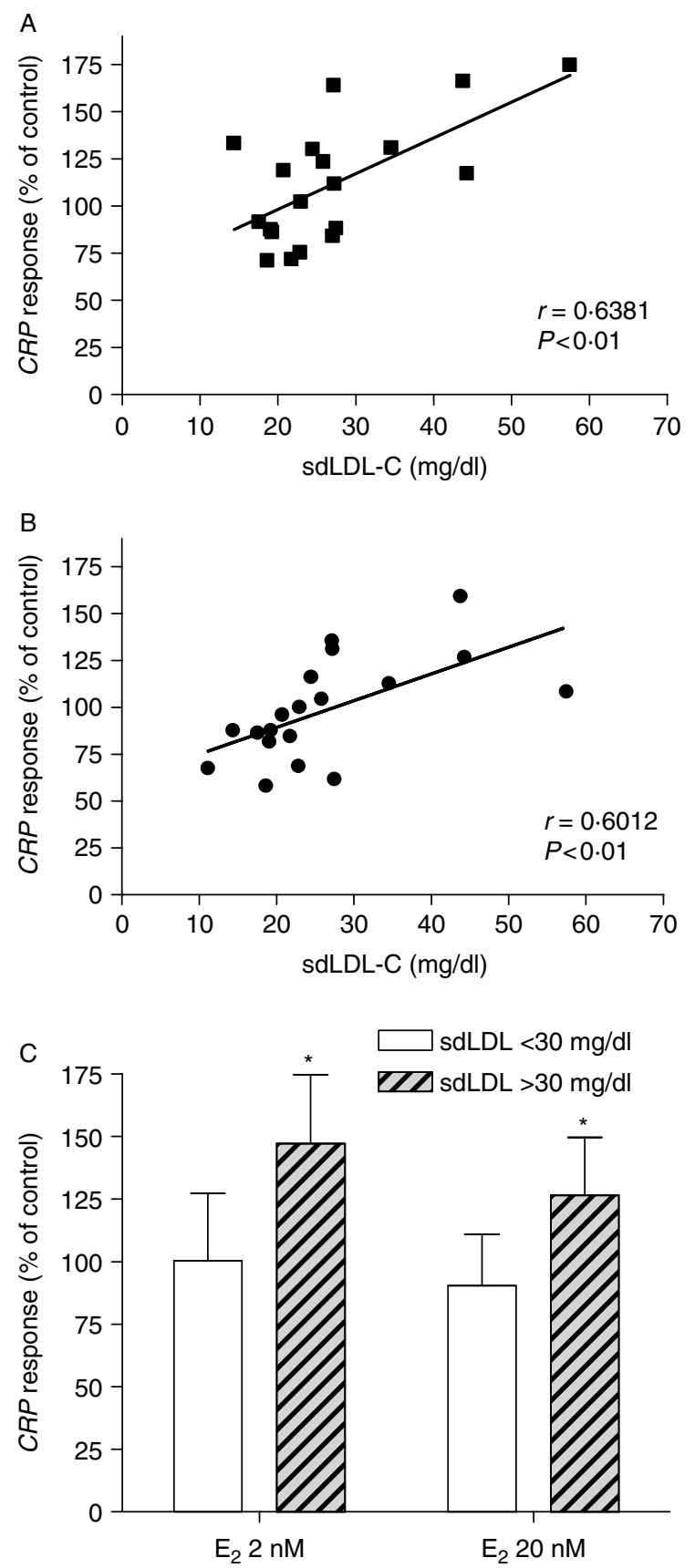

Figure 4 Association between fasting plasma sdLDL-C concentration of the donors and HMDM CRP gene expression in response to $\mathrm{E}_{2}$. (A) Association between the change in CRPexpression during $2 \mathrm{nME}_{2}$ treatment, relative to the control (vehicle), and the sdLDL-C levels of the donors. (B) Association between the change in CRP expression during $20 \mathrm{nM} \mathrm{E}_{2}$ treatment, relative to control (vehicle), and the sdLDL-C levels of the donors. Both the correlations were significant $(P<0 \cdot 01)$ and were gender independent. (C) Effect of $E_{2}$ on CRP expression as a function of the plasma sdLDL-C level of the donors. The number of subjects with sdLDL-C $<30 \mathrm{mg} / \mathrm{dl}$ is 12 , and the number of subjects with sdLDL-C $>30 \mathrm{mg} / \mathrm{dl}$ is 8 . Data are expressed as the percent of control; ${ }^{*} P<0 \cdot 05$. monocytes obtained from younger individuals (Chao et al. 1995, Kanda et al. 1996, 1997, D’Agostino Milano et al. 1999). Therefore, we hypothesized that similar changes would occur in HMDMs obtained from older individuals. In cells that were exposed to moderately oxidized LDLs, testosterone significantly reduced proinflammatory cytokine expression, specifically $T N F-\alpha$ and $I L-1 \beta$ expression, in agreement with the previous studies (Chao et al. 1995, Kanda et al. 1996, 1997, D’Agostino Milano et al. 1999). The effects of testosterone on TNF- $\alpha$ and IL-1 $\beta$ were observed at physiological and supraphysiological concentrations. Macrophages express the enzyme aromatase, and are therefore able to convert testosterone to $\mathrm{E}_{2}$ (Mor et al. 2001). Since reductions in TNF- $\alpha$ and IL-1 $\beta$ were only observed with testosterone, it is reasonable to assume that the effect observed with testosterone treatment was not due to aromatization to $\mathrm{E}_{2}$, but due to an androgen-specific action of testosterone.

$N F-\kappa B$ (NFKB), a transcription factor that plays a direct role in the expression of numerous proinflammatory cytokines including TNF- $\alpha$ and $I L-1 \beta$ (Li \& Verma 2002), may be the mediator of the repression of cytokine expression by testosterone. Several studies have shown that AR activation suppresses NF- $\kappa$ B activity (Hatakeyama et al. 2002, Libby 2002, Itoh et al. 2007), presumably by increasing the expression of $I k B-\alpha$ (NFKBIA; Death et al. 2004). NF-кB inhibition by testosterone is also associated with enhanced macrophage apoptosis (Cutolo et al. 2005), suggesting that the reduction in TNF- $\alpha$ expression is accompanied by an immunosuppressive effect.

The effect of $E_{2}$ on cytokine expression is less clear. Shortterm exposure to $\mathrm{E}_{2}(<1 \mathrm{~h})$ in vitro has been reported to decrease the production of proinflammatory cytokines in lipopolysaccharide (LPS)-activated rodent macrophages (Ghisletti et al. 2005). In contrast, several studies have reported that long-term exposure to $\mathrm{E}_{2}$ in vivo enhances the proinflammatory cytokine production in LPS-activated rodent macrophages (Soucy et al. 2005, Calippe et al. 2008). In our study, in which HMDMs obtained from 50- to 70-year-old male and postmenopausal female donors were cultured in the continual presence of $\mathrm{E}_{2}$, we observed no effect on proinflammatory cytokine expression compared with the vehicle-treated cells.

Randomized, placebo-controlled trials in postmenopausal women have shown that orally delivered, but not transdermally delivered, estrogen therapy increases plasma CRP concentrations (Cushman et al. 1999, Hodis et al. 2008). It has been speculated that hepatic metabolism of the orally delivered therapy is responsible for this rise in plasma CRP levels (Zegura et al. 2003). However, since CRP is also produced by macrophages in the aortic lesions, plasma CRP level changes in response to $\mathrm{E}_{2}$ treatment may not predict CRP changes in the arterial wall. Because CRP has been shown to elicit proatherogenic effects such as the promotion of macrophage cholesterol accumulation (Singh et al. 2008), CRP secreted by macrophages may play a role in lesion development. The CRP expression in response to $E_{2}$ treatment was quite variable in both female and male 
HMDM donors. It has been shown previously that the lipoprotein composition of culture serum may influence the cellular response (de la Llera Moya et al. 1994). Since HMDMs were cultured in $10 \%$ autologous serum, we tested the hypothesis that changes in CRP expression by $\mathrm{E}_{2}$ may be dependent on the plasma levels of lipoproteins of the donors. The CRP gene response to $\mathrm{E}_{2}$ was significantly correlated with plasma sdLDL-C levels, with a greater increase in $C R P$ expression in subjects with higher sdLDL-C levels. Individuals with a high concentration of sdLDL-C often display some degree of dyslipidemia and a greater degree of chronic inflammation and CHD (Vakkilainen et al. 2003, Krauss \& Siri 2004). This indicates that in a proatherogenic lipid environment, $\mathrm{E}_{2}$ may promote arterial disease, an effect that is not present under a healthy lipid environment. This concept is supported by clinical evidence suggesting that $E_{2}$ therapy is beneficial in younger premenopausal women, but harmful in older postmenopausal women (Rossouw et al. 2007). In support of our findings, a recent study done by Norata et al. (2009) has shown a greater expression of several proinflammatory molecules in HMDMs obtained from individuals with high sdLDL-C levels than in those obtained from individuals with lower sdLDL-C levels. Furthermore, in postmenopausal women, plasma sdLDL-C levels have been found to be significantly associated with plasma CRP concentration, further indicating the link between sdLDL-C and inflammation (Muzzio et al. 2007). We did not observe a significant correlation between these two factors in our study (data not shown). However, this may be due to the small sample size.

To our knowledge, our study is the first to report a modulation of CRP expression by $\mathrm{E}_{2}$ in HMDMs. The mechanism by which high sdLDL-C levels may alter the effect of $\mathrm{E}_{2}$ on CRP expression is not currently known. IL6 and $I L-1 \beta$ are the known stimulators of CRP expression (Calabro et al. 2003). In the current study and in the study done by Norata et al. (2009), sdLDL-C concentrations were not associated with HMDM IL6 expression. Similarly, the expression of IL 6 and $I L-1 \beta$ did not change with $\mathrm{E}_{2}$ treatment. Therefore, the observed up-regulation of macrophage CRP expression by $\mathrm{E}_{2}$ is not driven by greater macrophage IL6 or $I L-1 \beta$ expression. An IL6-independent stimulation of CRP by hormone replacement has also been suggested by observational and intervention studies (Lakoski \& Herrington 2005). The expression of Stat3, a transcription factor that regulates the expression of Crp , has been shown to be increased by estrogen in the ob/ob mouse model of obesity, possibly through Er $\alpha$ binding to the promoter region of Stat3 (Gao et al. 2006). How sdLDLs may modulate the effect of $\mathrm{E}_{2}$ on CRP expression is currently not known. sdLDLs are known to be in circulation longer than LDLs, and therefore are more likely to undergo oxidation (Millar \& Packard 1998).

Overall, these data suggest that testosterone may protect against the progression of atherosclerosis by inhibiting the expression of select proinflammatory cytokines in human macrophages, while $E_{2}$ may not be as potent in this regard.
Furthermore, $\mathrm{E}_{2}$ may actually encourage macrophage CRP production under conditions of high sdLDL-C, thereby potentially exacerbating atherosclerosis in individuals at risk of the disease. Understanding the mechanism of sdLDL$\mathrm{C}$-induced macrophage inflammation and how $\mathrm{E}_{2}$ modulates this is an important step in defining the role of both sdLDL-C and $\mathrm{E}_{2}$ in the progression of CHD.

\section{Declaration of interest}

The authors declare that there is no conflict of interest that could be perceived as prejudicing the impartiality of the research reported.

\section{Funding}

This work was supported by the United States Department of Agriculture, under agreement No. 58-1950-7-707 and T32 HL69772-01A1 (MPC). Any opinions, findings, conclusions, or recommendations expressed in this publication are those of the authors, and do not necessarily reflect the view of the USDA. MPC was supported by the Unilever Health Science Scholarship.

\section{Acknowledgements}

The authors thank Katalin V Horvath for measuring the plasma lipid and CRP concentrations of the volunteers.

\section{References}

Ai M, Otokozawa S, Asztalos BF, Nakajima K, Stein E, Jones PH \& Schaefer EJ 2008 Effects of maximal doses of atorvastatin versus rosuvastatin on small dense low-density lipoprotein cholesterol levels. American Journal of Cardiology 101 315-318.

Bisoendial RJ, Kastelein JJ, Peters SL, Levels JH, Birjmohun R, Rotmans JI, Hartman D, Meijers JC, Levi M \& Stroes ES 2007 Effects of CRP infusion on endothelial function and coagulation in normocholesterolemic and hypercholesterolemic subjects. Journal of Lipid Research 48 952-960.

Brown MS \& Goldstein JL 1983 Lipoprotein metabolism in the macrophage: implications for cholesterol deposition in atherosclerosis. Annual Reviews of Biochemistry 52 223-261

Calabro P, Willerson JT \& Yeh ET 2003 Inflammatory cytokines stimulated C-reactive protein production by human coronary artery smooth muscle cells. Circulation 108 1930-1932.

Calippe B, Douin-Echinard V, Laffargue M, Laurell H, Rana-Poussine V, Pipy B, Guery JC, Bayard F, Arnal JF \& Gourdy P 2008 Chronic estradiol administration in vivo promotes the proinflammatory response of macrophages to TLR 4 activation: involvement of the phosphatidylinositol 3-kinase pathway. Journal of Immunology 180 7980-7988.

Cathcart MK, McNally AK \& Chisolm GM 1991 Lipoxygenase-mediated transformation of human low density lipoprotein to an oxidized and cytotoxic complex. Journal of Lipid Research 32 63-70.

Chao TC, Van Alten PJ, Greager JA \& Walter RJ1995 1995 Steroid sex hormones regulate the release of tumor necrosis factor by macrophages. Cellular Immunology 160 43-49.

Cushman M, Legault C, Barrett-Connor E, Stefanick ML, Kessler C, Judd HL, Sakkinen PA \& Tracy RP 1999 Effect of postmenopausal hormones on inflammation-sensitive proteins: the Postmenopausal Estrogen/Progestin Interventions (PEPI) study. Circulation 100 717-722. 
Cutolo M, Accardo S, Villaggio B, Barone A, Sulli A, Coviello DA, Carabbio C, Felli L, Miceli D, Farruggio R et al. 1996 Androgen and estrogen receptors are present in primarycultures of human synovial macrophages. Journal of Clinical Endocrinology and Metabolism 81 820-827.

Cutolo M, Capellino S, Montagna P, Ghiorzo P, Sulli A \& Villaggio B 2005 Sex hormone modulation of cell growth and apoptosis of the human monocytic/macrophage cell line. Arthritis Research and Therapy 7 R1124-R1132.

D'Agostino P, Milano S, Barbera C, Di Bella G, La Rosa M, Ferlazzo V, Farruggio R, Miceli DM, Miele M, Castagnetta L et al. 1999 Sex hormones modulate inflammatory mediators produced by macrophages. Annals of the New York Academy of Sciences 876 426-429.

Death AK, McGrath KC, Sader MA, Nakhla S, Jessup W, Handelsman DJ \& Celermajer DS 2004 Dihydrotestosterone promotes vascular cell adhesion molecule-1 expression in male human endothelial cells via a nuclear factorkappaB-dependent pathway. Endocrinology 145 1889-1897.

Gao H, Bryzgalova G, Hedman E, Khan A, Efendic S, Gustafsson JA \& Dahlman-Wright K 2006 Long-term administration of estradiol decreases expression of hepatic lipogenic genes and improves insulin sensitivity in $\mathrm{ob} / \mathrm{ob}$ mice: a possible mechanism is through direct regulation of signal transducer and activator of transcription 3. Molecular Endocrinology 20 $1287-1299$.

Ghisletti S, Meda C, Maggi A \& Vegeto E 2005 17 $\beta$-Estradiol inhibits inflammatory gene expression by controlling NF-kappaB intracellular localization. Molecular and Cellular Biology 25 2957-2968.

Hak AE, Witteman JC, de Jong FH, Geerlings MI, Hofman A \& Pols HA 2002 Low levels of endogenous androgens increase the risk of atherosclerosis in elderly men: the Rotterdam study. Journal of Clinical Endocrinology and Metabolism 87 3632-3639.

Hatakeyama H, Nishizawa M, Nakagawa A, Nakano S, Kigoshi T \& Uchida K 2002 Testosterone inhibits tumor necrosis factor- $\alpha$-induced vascular cell adhesion molecule-1 expression in human aortic endothelial cells. FEBS Letters $\mathbf{5 3 0}$ 129-132.

Herrington DM, Howard TD, Hawkins GA, Reboussin DM, Xu J, Zheng SL, Brosnihan KB, Meyers DA \& Bleecker ER 2002 Estrogen-receptor polymorphisms and effects of estrogen replacement on high-density lipoprotein cholesterol in women with coronary disease. New England Journal of Medicine 346 967-974.

Hodis HN, St John JA, Xiang M, Cushman M, Lobo RA \& Mack WJ 2008 Inflammatory markers and progression of subclinical atherosclerosis in healthy postmenopausal women (from the Estrogen in the Prevention of Atherosclerosis Trial). American Journal of Cardiology 101 1131-1133.

Itoh Y, Hayashi $\mathrm{H}, \mathrm{Xu}$ J, Takii T, Miyazawa K, Ariga H, Akahoshi T, Waguri-Nagaya Y, Otsuka T, Okamoto T et al. 2007 Dihydrotestosterone inhibits tumor necrosis factor $\alpha$ induced interleukin- $1 \alpha$ mRNA expression in rheumatoid fibroblast-like synovial cells. Biological and Pharmaceutical Bulletin 30 1140-1143.

Kanda N, Tsuchida T \& Tamaki K 1996 Testosterone inhibits immunoglobulin production by human peripheral blood mononuclear cells. Clinical and Experimental Immunology 106 410-415.

Kanda N, Tsuchida T \& Tamaki K 1997 Testosterone suppresses anti-DNA antibody production in peripheral blood mononuclear cells from patients with systemic lupus erythematosus. Arthritis and Rheumatism 40 1703-1711.

Kobayashi S, Inoue N, Ohashi Y, Terashima M, Matsui K, Mori T, Fujita H, Awano K, Kobayashi K, Azumi H et al. 2003 Interaction of oxidative stress and inflammatory response in coronary plaque instability: important role of C-reactive protein. Arteriosclerosis, Thrombosis, and Vascular Biology 23 1398-1404.

Kramer PR, Kramer SF \& Guan G 2004 17ß-Estradiol regulates cytokine release through modulation of CD16 expression in monocytes and monocyte-derived macrophages. Arthritis and Rheumatism 50 1967-1975.

Krauss RM \& Siri PW 2004 Metabolic abnormalities: triglyceride and lowdensity lipoprotein. Endocrinology and Metabolism Clinics of North America 33 405-415.

Lakoski SG \& Herrington DM 2005 Effects of hormone therapy on C-reactive protein and IL-6 in postmenopausal women: a review article. Climacteric 8 317-326.
Li Q \& Verma IM 2002 NF- $\kappa B$ regulation in the immune system. Nature Reviews. Immunology 2 725-734.

Li L, Roumeliotis N, Sawamura T \& Renier G 2004 C-reactive protein enhances LOX-1 expression in human aortic endothelial cells: relevance of LOX-1 to C-reactive protein-induced endothelial dysfunction. Circulation Research $95877-883$.

Libby P 2002 Inflammation in atherosclerosis. Nature 420 868-874.

de la Llera Moya M, Atger V, Paul JL, Fournier N, Moatti N, Giral P, Friday KE \& Rothblat G 1994 A cell culture system for screening human serum for ability to promote cellular cholesterol efflux. Relations between serum components and efflux, esterification, and transfer. Arteriosclerosis and Thrombosis 14 1056-1065.

Lloyd-Jones D, Adams R, Carnethon M, De Simone G, Ferguson TB, Flegal K, Ford E, Furie K, Go A, Greenlund K et al. 2009 Heart disease and stroke statistics - 2009 update: a report from the American Heart Association Statistics Committee and Stroke Statistics Subcommittee. Circulation 119 480-486.

Millar JS \& Packard CJ 1998 Heterogeneity of apolipoprotein B-100-containing lipoprotein: what we have learnt from kinetic studies. Current Opinion in Lipidology 9 197-202.

Mor G, Eliza M, Song J, Wiita B, Chen S \& Naftolin F 2001 17 $\alpha$-Methyl testosterone is a competitive inhibitor of aromatase activity in Jar choriocarcinoma cells and macrophage-like THP-1 cells in culture. Journal of Steroid Biochemistry and Molecular Biology 79 239-246.

Muzzio ML, Berg G, Zago V, Basilio F, Sanguinetti S, Lopez G, Brites F, Wikinski R \& Schreier L 2007 Circulating small dense LDL, endothelial injuring factors and fibronectin in healthy postmenopausal women. Clinica Chimica Acta 381 157-163.

Norata GD, Raselli S, Grigore L, Garlaschelli K, Vianello D, Bertocco S, Zambon A \& Catapano AL 2009 Small dense LDL and VLDL predict common carotid artery IMT and elicit an inflammatory response in peripheral blood mononuclear and endothelial cells. Atherosclerosis 206 556-562.

Pradhan AD, Manson JE, Rossouw JE, Siscovick DS, Mouton CP, Rifai N, Wallace RB, Jackson RD, Pettinger MB \& Ridker PM 2002 Inflammatory biomarkers, hormone replacement therapy, and incident coronary heart disease: prospective analysis from the Women's Health Initiative observational study. Journal of the American Medical Association 288 980-987.

Rossouw JE, Prentice RL, Manson JE, Wu L, Barad D, Barnabei VM, Ko M, LaCroix AZ, Margolis KL \& Stefanick ML 2007 Postmenopausal hormone therapy and risk of cardiovascular disease by age and years since menopause. Journal of the American Medical Association 297 1465-1477.

Singh U, Dasu MR, Yancey PG, Afify A, Devaraj S \& Jialal I 2008 Human C-reactive protein promotes oxidized low density lipoprotein uptake and matrix metalloproteinase-9 release in Wistar rats. Journal of Lipid Research 49 1015-1023.

Soucy G, Boivin G, Labrie F \& Rivest S 2005 Estradiol is required for a proper immune response to bacterial and viral pathogens in the female brain. Journal of Immunology 174 6391-6398.

Tipping PG \& Hancock WW 1993 Production of tumor necrosis factor and interleukin-1 by macrophages from human atheromatous plaques. American Journal of Pathology 142 1721-1728.

Torres JL \& Ridker PM 2003 Clinical use of high sensitivity C-reactive protein for the prediction of adverse cardiovascular events. Current Opinion in Cardiology 18 471-478.

Vakkilainen J, Steiner G, Ansquer JC, Aubin F, Rattier S, Foucher C, Hamsten A \& Taskinen MR 2003 Relationships between low-density lipoprotein particle size, plasma lipoproteins, and progression of coronary artery disease: the Diabetes Atherosclerosis Intervention Study (DAIS). Circulation 107 1733-1737.

Valente AJ, Rozek MM, Sprague EA \& Schwartz CJ 1992 Mechanisms in intimal monocyte-macrophage recruitment. A special role for monocyte chemotactic protein-1. Circulation 86 III20-III25.

Vieira OV, Laranjinha JA, Madeira VM \& Almeida LM 1996 Rapid isolation of low density lipoproteins in a concentrated fraction free from watersoluble plasma antioxidants. Journal of Lipid Research 37 2715-2721.

Williams TN, Zhang CX, Game BA, He L \& Huang Y 2004 C-reactive protein stimulates MMP-1 expression in U937 histiocytes through 
Fc[gamma]RII and extracellular signal-regulated kinase pathway: an implication of CRP involvement in plaque destabilization. Arteriosclerosis, Thrombosis, and Vascular Biology 24 61-66.

Yasojima K, Schwab C, McGeer EG \& McGeer PL 2001 Generation of $\mathrm{C}$-reactive protein and complement components in atherosclerotic plaques. American Journal of Pathology 158 1039-1051.

Yesilova Z, Ozata M, Kocar IH, Turan M, Pekel A, Sengul A \& Ozdemir IC 2000 The effects of gonadotropin treatment on the immunological features of male patients with idiopathic hypogonadotropic hypogonadism. Journal of Clinical Endocrinology and Metabolism 85 66-70.
Zegura B, Keber I, Sebestjen M \& Koenig W 2003 Double blind, randomized study of estradiol replacement therapy on markers of inflammation, coagulation and fibrinolysis. Atherosclerosis 168 123-129.

Received in final form 26 April 2010

Accepted 18 May 2010

Made available online as an Accepted Preprint 18 May 2010 